\title{
Comparative Analysis on Financial Performance and Sustainable Incentives in the Construction Sector. Evidence from the Coastal Area of Romania
}

\author{
Ionela FLOREA MUNTEANU ${ }^{\star}$
}

\begin{tabular}{l}
\hline \multicolumn{1}{c}{ A R T I C L E I N F O } \\
\hline Article history: \\
Accepted April 2021 \\
Available online April 2021 \\
\hline JEL Classification \\
L79, N60, P51 \\
Keywords: \\
Construction industry, Financial \\
performance, Sustainable \\
development, Comparative \\
analysis
\end{tabular}

\begin{abstract}
A B S T R A C T
A testimony of local development resides in infrastructure, thus the construction industry shapes the image of cities, reflects the past of strives to an innovative future. The economic aspects of the construction industry reveal treands, interest areas or perspectives of sustainable development. The current study develops a statistical explicative investigation on how the construction industry has developed in the coastal area in Romania, by conducting a comparative analysis on construction businesses between the two counties in the area, Constanta and Tulcea. The results point to interesting divergent trends between the two neighbor counties and present interest to enhance the comparative analitical area of contruction research, to local governance, practitioners and potential investors.
\end{abstract}

(C) 2021 EAI. All rights reserved.

\section{Introduction}

Information is sensitive and is shaped by a set of managerial rules and decisions. Data disclosure channels and considerations that could affect a company's financial reporting options have multiple deterministic perspectives which, if assessed in the context of the activity sector business trends, become of utmost importance for assessing the sustainability drivers. As previous studies have demonstrated, the disclosure of business performance regarding sustainability reporting, which encompasses financial aspects and responsible behavior, environment and social impact (Stan et al., 2019), lags in the construction sector (Glass, 2012).

Financial reporting includes historical business information for the purpose of supporting managers during the process of forecasting cash flows and future business investments. Researchers in the field of accounting have examined various aspects of the decision-making process related to financial reporting using various theories or methods of empirical analysis.

The current study strives to fill the gap identified by the lack of information availability and the use of analytics in construction that underlies the interpretation of the dynamics and trends of construction indicators in different areas (Naderpajouh, 2016). The main objective of the paper is to expand the field of knowledge by developing an economic perception in the field of construction, based on the diachronic exploration of financial indicators and the empirical observation of trends or disparities. The predilection for business and the perspective of sustainable development in Romania's two counties by the sea, Constanta and Tulcea, are widened by the comparative and progressive analysis between several relevant business indicators reported by the construction companies acting in the region. The findings on local construction business trends in Romania's coastal area raise awareness on the need for a broader vision of local sustainable development and investment improvement strategies focused on supporting the industry and the systematic environment strategies.

\section{Literature review}

The role of construction industry in reaching economic growth (Utama et al., 2011) was researched from multiple perspectives, from engineers' interpretation of pressure effects (Nepal, 2006) to economic performance measurement (Bassioni et al., 2004). Researchers approached the construction performance with input-output assessment indicators between emerging countries (Gregori \& Pietroforte, 2015) or key performance indicators for benchmark measuring research (Chan \& Chan, 2004), from managerial theoretical implications of sense-making (Möller, 2010) and managerial decision to performance measurement systems based on financial and non-financial indicators in construction (Takim et al., 2003). The assessment of the 
financial position of companies operating in the construction industry has been developed with various criteria and methods (Ginevičius, 2011).

The importance of corporate social responsibility (CSR) in the construction industry determined various research initiatives based in many cases on surveys. The results showed that CSR knowledge is scarce in this sector and that its' linkage to economic performance resides mainly in operational and compliancebased approaches, rather than on strategic thinking (Loosemore and Lim, 2017). The need for a strategic approach in the construction industry is also supported by factual trends in Romania. The link between construction indicators and net nominal earnings (Mirea and Aivaz, 2016), or with tourism or local development motivates the research from an empirical perspective.

The regulatory attention in Romania driven by the principles of sustainable development has contributed to the development of new regulations regarding the construction rules in protected areas, such as the Danube Delta, the coastal area, the Carpathians or other protected areas. The new regulations are adopted in the context of the current chaos in the construction sector presented by media, of the little care for environmental impact of new buildings and is triggered by the need to assess sustainable development perspectives.

The focus of the current study is set particularly on the financial dimension of the construction industry in the coastal area, and on the observation of the different similarities or disparities between the predilection for operational subdomains of the construction field in order to determine incentives for sustainable development in this economic sector. The limitations of the study reside in the scarcity of public data that can allow the development of comparative research on construction financial indicators between different protected areas. Nevertheless, the current analysis strives to raise interest in the financial analysis of construction financial indicators and contributes with extensive valuable research data from the coastal area of Romania.

Comparative studies focused on financial aspects in the same region drew concerns on the need to further develop studies oriented to sustainable strategies and to the enhancement of business knowledge awareness (Aivaz, 2020).

\section{Methodology}

The data allows a valuable comparative and explicative diachronic analysis which highlights the interdependencies between the two counties located in the coastal area of the Black Sea, Constanta and Tulcea. The quantitative analysis on relevant financial indicators is enhanced by the calculated progression trends and the three-years forecasted evolution which is developed for each construction subsector.

The research employs a comparative and progressive analysis between Constanța and Tulcea concerned with the businesses in the construction sector. The focus is set on a series of financial indicators extracted from the acting companies' financial reports. Financial reporting is an important component of sustainable economic development, which supports the forecast of business growth in the targeted regions. The progressive investigation endorses a perspective on the profitability of the coastal construction sector, highlighting the observations for each construction subdomain (Chang et al., 2018).

\section{Description of data}

According to theorists, the selection of variables based on experts' professional judgement is considered to be subjective (Podvezko \& Podviezko, 2010). This paper does not add criteria to the financial indicators included in the sample analysis, but uses general financial indicators extracted from the financial statements and which can be used for statistical comparison with similar indicators in other regions.

The variables were collected from financial reports of the companies acting in the construction sector during 2014-2018. The chosen variables consist of positive reported financial indicators, categorized by construction subsector in the two counties, Constanta and Tulcea: fixed assets, turnover, operating expenses and gross profit. In order to harmonize the differences between the size of the reporting companies and to observe the annual trends for each subsector, the average values of the selected indicators were analysed.

Specific to the regulations of construction industry is the fact that the activities of companies are classified into different subdomains that together form the construction sector. The investigated database took each of these subdivisions into account when reflecting the comments.

The subdomains established in the field of constructions according to the Romanian legislation, contain: construction companies acting in real estate development (Real estate Constr), construction works for residential and non-residential buildings (Building Constr), road and railway construction works (Road building), construction works for utility projects (Utility projects), construction works for engineering projects (Engineering projects), demolition and land preparation works (Demol.\&land preparation), electrical and sanitary installation works and other construction installation works (Electric\&sanitary instalation), finishing works in constructions (Finishing works), other special construction works (Other construction works). 


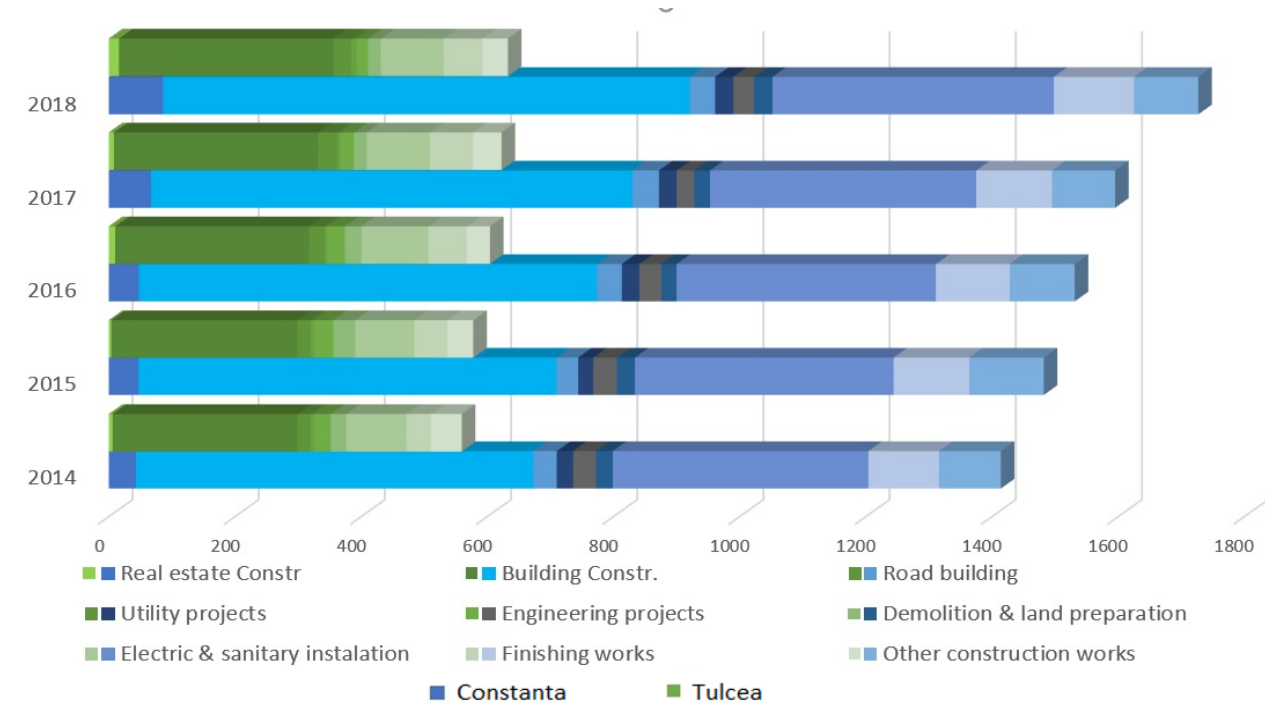

Figure 1. The evolution of the number of construction companies in Constanta and Tulcea, Romania Source: author's representation based on the data provided by the Romanian Ministry of Finance

The findings of the analysis are substantiated by the extensive population of reported indicators included in the study. According to Figure 1, the comparative representation between the number of companies acting in each construction subdomain shows that in Constanta the number of companies is much higher than in Tulcea. Observed in dynamics, the number of construction companies in Constanta increased with 22\% in the year 2018 compared to 2014, whereas in Tulcea the growth in number reached 13\%. In both counties, the subsector with the highest number of companies represents construction activities for residential and non-residential buildings (Buiding $\mathrm{Co}$ ), followed by electrical and sanitary installation works (Electric \& sanitary installation). The engineering projects subdomain underwent a decrease in the number of acting companies in both targeted counties.

The analysis reveals that the business trends in the field of construction show noticeable upward tendencies in Constanţa, which are incentives for local economic development.

\section{Findings and considerations}

The comparative evolution of financial indicators between Constanța and Tulcea illustrates interesting trends in the two counties and disparate predilections for construction activities. The divergent progressions for construction subsectors in the two counties point to dichotomous orientations for economic development. As a first general observation regarding the comparison of the economic indicators between the two regions, during the entire investigated period, the indicators reported by companies in Constanța had higher means than the financial indicators reported in Tulcea County.

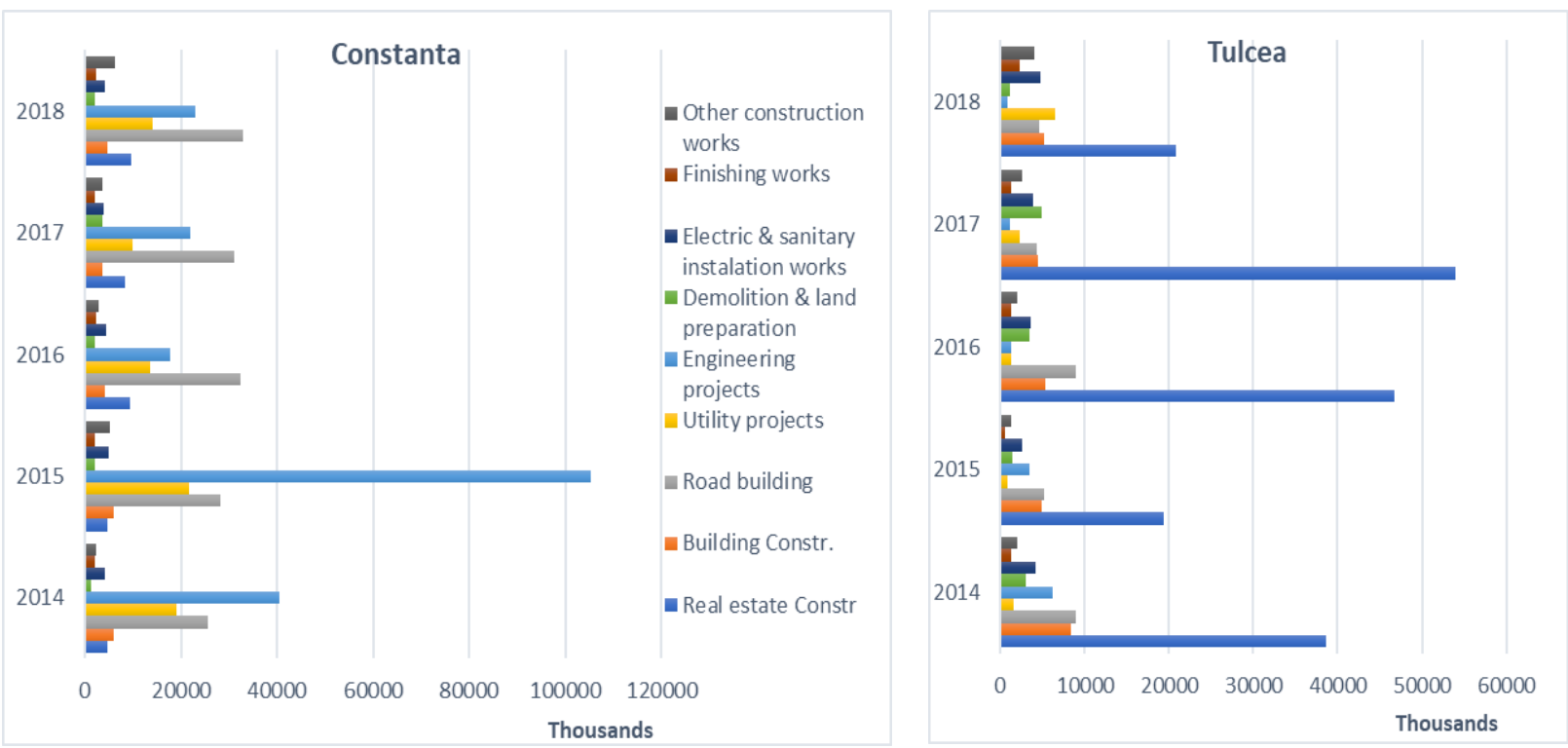

Figure 2. The evolution of medium turnover, for each construction subsectors, in Constanta and Tulcea Source: author's representation based on the data provided by the Romanian Ministry of Finance 
Figure 2 shows the financial performances on the construction activity subdomains between the two coastal areas, reflected by the average turnover of the reporting profitable companies.

According to the visual representation of turnover in Figure 2 above, relevant turnover values were reported by companies in Constanta for the engineering projects activities (Engineering projects), road building and utility projects. Engineering projects in Constanta represent works for estate building projects that are sold for lodging mainly for touristic reasons, and also for naval engineering works. In Tulcea county, the highest turnover was reported in the real estate construction subsector, whereas the other construction subdomains present fairly homogenous indicators.

Considering the turnover trends in the two areas, an incentive for development in the real estate sector may be observed in both targeted areas, but a more visible predilection for road infrastructure and utility projects is better observed in Constanta. An active concern for urbanization and touristic development implies a particular focus on road infrastructure, accessibility and utility facilities in emerging economies. Thus, the turnover medium rates point to a better care in this respect in Constanta county.

The next financial indicators reported by construction companies taken into analysis were the medium fixed assets, presented in evolution in Figures 3 and 4.

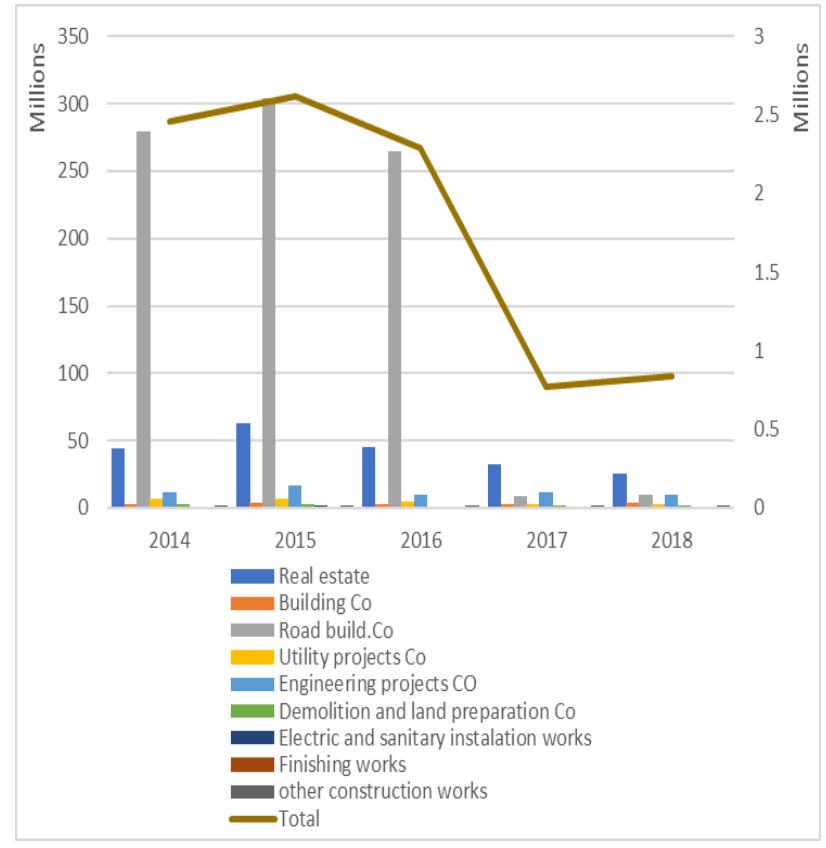

Figure 3. The evolution of medium fixed assets, for each construction subsectors, in Constanta, Romania

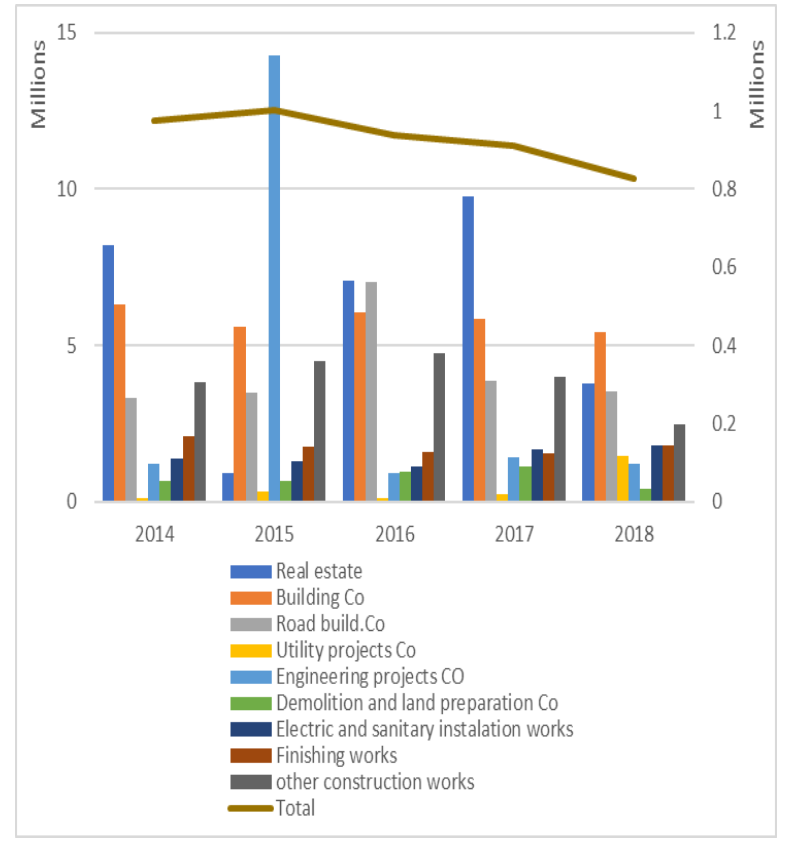

Figure 4. The evolution of medium fixed assets, for each construction subsectors, in Tulcea, Romania each construction subsectors, in Tulce
provided by the Romanian Ministry of Finance

The graphical trends observed according to Figures 3 and 4 show that the evolution of medium fixed assets in Constanta reached their peaks in 2015 with evident depiction in the road building subsector, followed by an abrupt downward trend in 2017. The decrease may be attributed to accounting evidence reasons, since the road building in Constanta is mainly developed by SOEs, that during 2014-2016 reported in their financial reports the investments in the public road infrastructure followed by the ceasing of the obtained assets to the local public authorities at the end of the projects. The high indicators reported during 2014-2016 show extensive projects in the road building subsector and important local budget allocation during the period for road building or improvement. The other subsectors are illustrated at lower levels for fixed assets indicators, among which the real estate presence is the most notable. In Constanta extensive building was developed in the analysed period mainly in the seaside areas near the main city of Constanta and Mamaia, especially for touristic development reasons.

The indicators for main fixed assets in Tulcea present a stable slightly downward trend, with predilection for real estate and building subsectors suggestive figures.

The evolution of reported average operational trends is graphically presented in Figures 5 and 6. 


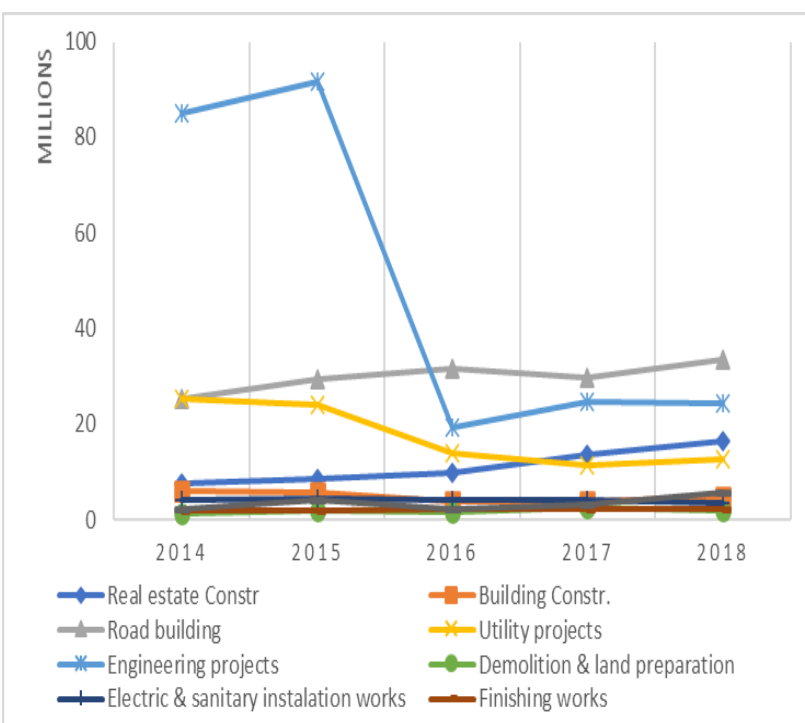

Figure 5. The evolution of medium operational costs, for each construction subsectors, in Constanta, Romania

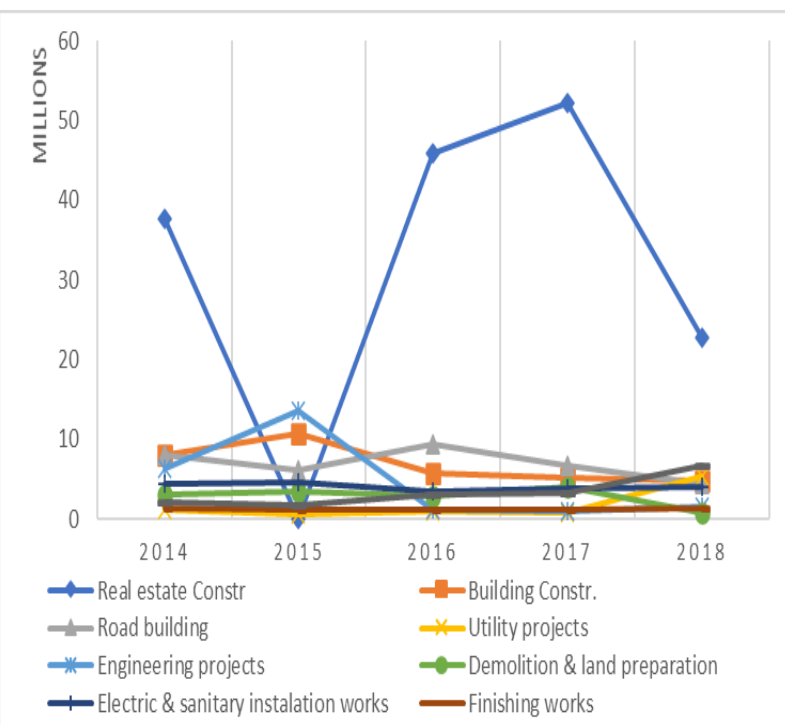

Figure 6. The evolution of medium operational costs, for each construction subsectors, in Tulcea, Romania

Source: author's representation based on the data provided by the Romanian Ministry of Finance

The evolutions of the analysed indicators present progression patterns similar to those observed for the medium reported turnover, presented in Figure 2. The mostly fluctuating trends are perceived in engineering projects in Constanta and real estate in Tulcea, construction subsectors that were also the most visible for turnover financial development.

The financial indicators took into analysis for the construction industry in the Dobruja region, allowed us to project forecasted trends for the medium gross profits, for each investigated construction subsector, as shown in Figures 7 and 8. The results are of great value in order to get a provisioned picture of the construction financial development trends in the two geographically connected areas. Also, the medium gross profit trends can be better observed with the linear graphic progressions. A three years estimated trend could be calculated based on the reported financial indicators for each activity subsector. It is interesting to continue the analysis once the indicators are realised, centralised and communicated by the public authorities, in order to compare the forecasted trends with the actual financial results.

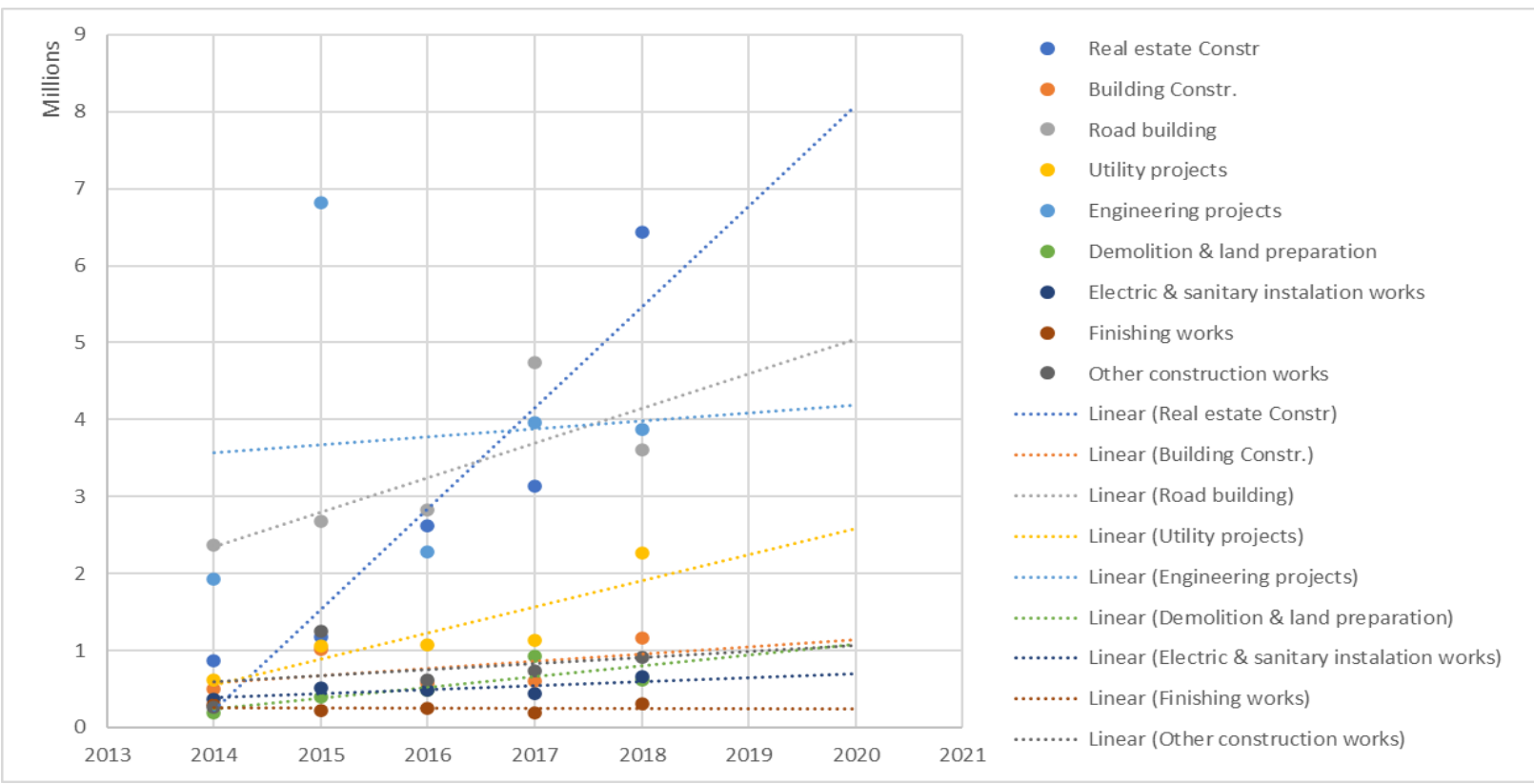

Figure 7. Forecast of medium gross profit for each construction subsectors, in Constanta, Romania Source: author's representation based on the data provided by the Romanian Ministry of Finance

Figure 7 shows a favourable forecasted evolution of gross profits for each construction subsector, in Constanta. The financial indicators show that the most profitable businesses developed in construction industry in the area are the ones acting in the real estate subsector, followed by road building companies, 
engineering projects companies and utility projects businesses. The forecasted profitable areas point to a developing trend that should bring new accommodations, roads and accessibility infrastructure to Constanta County. The trend suggests incentives for economic enhancement, impetus for quality of living and touristic development.

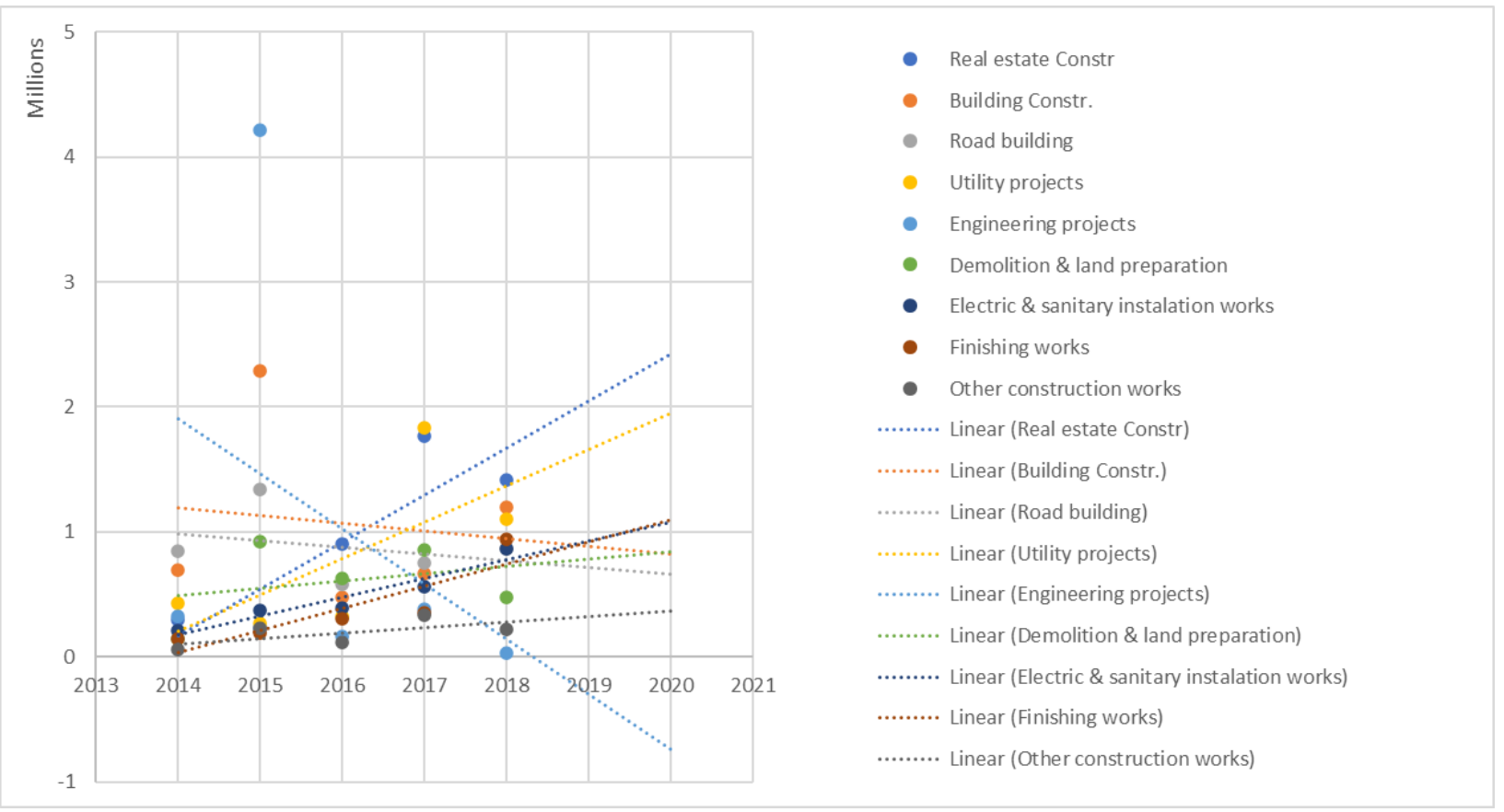

Figure 8. Forecast of medium gross profit for each construction subsectors, in Tulcea, Romania Source: author's representation based on the data provided by the Romanian Ministry of Finance

The current analysis points to divergent trends for business evolution in the construction sector in Tulcea, according to Figure 8. There are some construction sectors that point to mild profitability decrease, such as the building and the road building subsectors, while the engineering projects show an abrupt descending projection. The other construction subsectors present mild forecasted profit improvements, but the projected trends seem to not follow a very decisive pattern. The construction subsectors that present decreasing tendencies raise development concern, that should draw the local governance interest into investments revival and local infrastructure development.

\section{Conclusions}

The main results of this analysis on business statistics in the construction industry in Constanta and Tulcea are important from a dual perspective. On the one hand, the investigated financial indicators are accounted for in forecasted performance indicators for the construction subsectors. The findings point to future development perspectives of the construction industry that may influence the economic and social indicators of the local community.

On the other hand, the construction sector contributes significantly to the real estate or local touristic development. The observation of financial trends in this domain presents interesting incentives for local progress trends and perspectives to reduce local poverty. However, local governance should be concerned with implementing long-term sustainable strategies for construction sectors, in order to achieve economic progress with respect and care for the preservation of the local environment.

The value of the results resides in the multitude of practical implications. Accounting indicators and financial reporting encompass an enormous potential for representing the economic context and the operational inflections in the social and environmental spheres. The construction industry is an engine for the regional economy, which inflects impulse to the development of tourism, agriculture, transports, services and trade. The analysis of business trends in the construction industry provides valuable incentives for the local development and allows reasonable provisions of strategic economic importance for researchers, local governance, practitioners and potential investors. The disparities between Constanta and Tulcea in the construction industry in terms of road infrastructure, real estate objectives, engineering projects prove to be key drivers for economic development.

The results of the study indicate, for the case of the coastal region of Romania, the need for effective business oriented regulatory strategies that may support the development of companies operating in the construction industry. The perspective of sustainable development enhances the need for a strategic vision in the construction industry. Even though the two observed neighbor counties have similar strategic potential, 
because of their geographical position in the coastal area, their great touristic potential and the direct access to both the Black Sea and the Danube Delta, the financial performance forecasted trends in construction show a wide set of disparities and different forecasted trends. The construction industry plays a key role in the local development, thus, the enhancement of financial comparative analysis with other coastal areas may bring valuable sustainable economic incentives.

\section{References}

1. Aivaz, K. A. (2020). Considerations on Asset Management and Turnover Factorial Correlations: The Case of Dobrogea Region, Rom ania. Ovidius University Annals, Series Economic Sciences, 20(2).

2. Utama, N.A., Ishihara, K.N., Tezuka, T., Zhang, Q. and Esteban, M. (2011) Transportation's Impact Assessment on Construction Sector. Low Carbon Economy, 2, 152-158. http://dx.doi.org/10.4236/lce.2011.23019.

3. Nepal, M. P., Park, M., \& Son, B. (2006). Effects of schedule pressure on construction performance. Journal of Construction Engineering and Management, 132(2), 182-188.

4. Bassioni, H. A., Price, A. D., \& Hassan, T. M. (2004). Performance measurement in construction. Journal of management in engineering, 20(2), 42-50.

5. Glass, J. (2012), "The state of sustainability reporting in the construction sector", Smart and Sustainable Built Environment, Vol. 1 No. 1 , pp. 87-104. https://doi.org/10.1108/20466091211227070.

6. Gregori, T., \& Pietroforte, R. (2015). An input-output analysis of the construction sector in emerging markets. Construction management and economics, 33(2), 134-145.

7. Chan, A. P., \& Chan, A. P. (2004). Key performance indicators for measuring construction success. Benchmarking: an international journal.

8. Mirea, M., \& Aivaz, K. A. (2016). Analyzing "the workforce cost" and "the net nominal earnings" in the main economic activiti es, by principal component analysis. In Basiq International Conference-New Trends in Sustainable Business and Consumption, pp. 201-208.

9. Möller, K. (2010). Sense-making and agenda construction in emerging business networks - How to direct radical innovation. Industrial Marketing Management, 39(3), 361-371.

10. Takim, R., Akintoye, A., \& Kelly, J. (2003, September). Performance measurement systems in construction. In 19th annual ARCoM conference (Vol. 1, pp. 423-432). University of Brighton, Association of Researchers in Construction Management.

11. Ginevičius, R. (2011). A new determining method for the criteria weights in multicriteria evaluation. International Journal of Information Technology \& Decision Making, 10(06), 1067-1095.

12. Loosemore, M., \& Lim, B. T. H. (2017). Linking corporate social responsibility and organizational performance in the construction industry. Construction management and economics, 35(3), 90-105.

13. Naderpajouh, N., Choi, J., \& Hastak, M. (2016). Exploratory framework for application of analytics in the construction industry. Journal of Management in Engineering, 32(2), 04015047.

14. Chang, R. D., Zuo, J., Zhao, Z. Y., Soebarto, V., Lu, Y., Zillante, G., \& Gan, X. L. (2018). Sustainability attitude and performance of construction enterprises: A China study. Journal of cleaner production, 172, 1440-1451.

15. Podvezko, V., \& Podviezko, A. (2010). Dependence of multi-criteria evaluation result on choice of preference functions and their parameters. Technological and Economic Development of Economy, 16(1), 143-158.

16. Stan, M. I., Aivaz, K. A., \& Ionițiu, I. (2019). Projects to Reduce the Coastal Erosion of the Romanian Black Sea Area. Ovidius University Annals, Series Civil Engineering, 21(1). 